\title{
MONITORAMENTO EM LONGO PRAZO DA CONTENÇÃO VEGETATIVA EM TALUDE RODOVIÁRIO DE SAPROLITO DE GNAISSE EM MINAS GERAIS ${ }^{(1)}$
}

\author{
Rosilene Einloft ${ }^{(2)}$, Hugo Alberto Ruiz ${ }^{(3)}$, Liovando Marciano da Costa ${ }^{(4)}$, Carlos Ernesto \\ Gonçalves Reynaud Schaefer ${ }^{(4)}$, James Jackson Griffith ${ }^{(5)}$, Wilson Marcelo da Silva \\ Junior $^{(6)}$ \& Renato Ribeiro Passos ${ }^{(7)}$
}

\begin{abstract}
RESUMO
A sucessão de eventos após a revegetação de uma área, em geral, não é estudada. Com o passar do tempo, um consórcio vegetal que se apresentou favorável na fase inicial pode não ser adequado no futuro, deixando a área com o solo descoberto e suscetível à ação dos fatores intempéricos. $O$ objetivo deste trabalho foi monitorar características associadas à contenção vegetativa e, em longo prazo, o surgimento de novas formas de cobertura ou exposição do solo em resposta à revegetação com gramíneas e leguminosas em talude rodoviário de declividade acentuada. Após quatro anos, foi observada, nas parcelas experimentais, a presença de novas formas de cobertura ou exposição do solo, denominadas tipologias, como: cobertura de braquiária, leguminosa, capim-gordura, espécies invasoras, biomanta, resíduos em decomposição, crostas microfíticas, crosta física, solo exposto, erosão e afloramento de rochas. Essas tipologias foram quantificadas em dois levantamentos: antes e após o período chuvoso. Foram confeccionados mapas de cobertura para cada parcela experimental e analisadas a dinâmica, distribuição espacial, frequência e competição entre as tipologias encontradas nos dois levantamentos. Das 11 tipologias encontradas, as espécies vegetais e as crostas microfíticas foram as mais importantes no estádio primário da sucessão ecológica,
\end{abstract}

(1) Parte da Tese de Doutorado do primeiro autor apresentada à Universidade Federal de Viçosa. Recebido para publicação em 13 de setembro de 2012 e aprovado em 09 de novembro de 2012.

${ }^{(2)}$ Eng. Florestal, Ambiente Gaia Consultoria. Rua Otávio Silva Araújo, 7. CEP 36.570-000 Viçosa (MG). E-mail: reinloft@uol.com.br

(3) Professor Visitante Nacional Sênior do Centro de Ciências Agrárias, Universidade Federal do Espírito Santo, Alto Universitário, s/n. CEP 29500-000 Alegre (ES). Bolsista CAPES e CNPq. E-mail: hruiz@cca.ufes.br, hruiz@ufv.br.

(4) Professor ,Departamento de Solos, Universidade Federal de Viçosa - DPS/UFV. Av. P.H. Rolfs, s/n. CEP 36571-000 Viçosa (MG). Bolsista do CNPq. E-mail: liovandomc@yahoo.com.br; carlos.schaefer@ufv.br

(5) Professor, Departamento de Engenharia Florestal, UFV. E-mail: griffith@ufv.br

(6) Biólogo, EIAS Consultoria Ambiental. Rua Capitão Emídio, 89. CEP 13416-040 São Pedro (SP). E-mail: wmarcelo@eiasconsultoria.com.br

(7) Professor, Departamento de Produção Vegetal, Universidade Federal do Espírito Santo, Alto Universitário, s/n. CEP 29500000. Bolsista do CNPq. E-mail: renatoribeiropassos@hotmail.com 
resultando em rápida estabilização e recuperação da superfície degradada e favorecendo o aparecimento de espécies invasoras. A variação sazonal entre os dois levantamentos levou à diminuição da erosão e ao solo exposto, pelo incremento da cobertura vegetal e das crostas microfíticas.

\author{
Termos de indexação: revegetação, mapas de cobertura, recuperação de áreas \\ degradadas.
}

\title{
SUMMARY: LONG-TERM MONITORING OF VEGETATIVE STABILIZATION OF A ROAD SLOPE OF GNAISSE SAPROLITE IN MINAS GERAIS
}

\begin{abstract}
The succession of events after revegetation has rarely been studied. A plant consortium with a good initial development may come to be inadequate later, resulting in exposed soil, susceptible to the weathering forces. The objective of this study was to monitor characteristics associated with vegetative stabilization and, in the long term, the appearance of new cover forms or soil exposure in response to planting grasses and legumes on a steep road slope alongside a highway. After four years of recovery, new forms of soil cover or exposure were observed in the experimental plots, called typologies, described below: brachiaria grass cover, legume plants, gordura grass, invasive species, geotextile, decomposing residues, microphytic crusts, soil crust, exposed soil, erosion, and rock outcrops. The characteristics of these typologies were quantified by two surveys, before and after the rainy season. In addition, the different typologies of each experimental plot were mapped; these maps were used to analyze the dynamics, spatial distribution, frequency, and competition among typologies identified in the two surveys. Of the total 11 typologies, the vegetation species and microphytic crusts were the most relevant for revegetation. Microphytic crusts were very important in the initial stage of ecological succession, resulting in rapid stabilization and reclamation of degraded surfaces and favoring the appearance of invasive species. The seasonal variation between the two surveys showed that erosion and soil exposure decreased with increase in vegetation cover and microphytic crust development.
\end{abstract}

Index terms: revegetation, ground cover maps, degraded land reclamation.

\section{INTRODUÇÃO}

Após a retirada da cobertura natural do solo para abertura de estradas, a substituição da vegetação é fundamental para o restabelecimento da área perturbada. Entretanto, ainda hoje, observam-se áreas sujeitas ao processo de regeneração natural. Nesse processo, mais lento, o sistema está submetido a fatores como exposição solar, impacto direto da chuva, distância e qualidade da fonte de propágulos. Para reduzir o tempo de revegetação, pesquisas têm sido realizadas para a escolha de espécies, em que as características favoráveis se baseiam em rápida germinação, crescimento radicular, cobertura vegetal e baixa exigência nutricional, entre outras (Bochet \& García-Fayos, 2004; Foster et al., 2007; Einloft et al., 2009). Fatores como declividade do terreno e face de exposição ao sol influenciam as propriedades do solo, a cobertura vegetal, a riqueza de espécies, a composição florística e a erosão hídrica (Bochet \& García-Fayos, 2004). Com relação ao método de revegetação empregado, algumas técnicas têm sido adotadas pelo setor rodoviário como hidrossemeadura, uso de biomanta, uso de serapilheira e topsoil (Einloft et al., 2000). Em estudo de revegetação de encostas de talude rodoviário em Mesa Verde National Park, EUA,
Paschke et al. (2000) avaliaram técnicas como fertilização, cobertura morta, coveamento e transplantio de espécies e utilização de polímero poliacrilamida, verificando que a adição de fertilizante orgânico, em combinação com a cobertura morta, foi o método mais eficaz para melhoria da vegetação de cobertura e de outras espécies transplantadas. No entanto, além da escolha das espécies e da técnica apropriada, alguns cuidados devem ser observados. Griffith et al. (1994) sugeriram que a revegetação de áreas degradadas deve ser realizada obedecendo a duas fases. A primeira fase visa à promoção do recobrimento rápido do solo com vegetação receptiva ao início do processo sucessional; em uma fase posterior, deve-se manipular a dinâmica sucessional, levando a um sistema autossustentável.

Isso sugere que, ao se recomendar determinado consórcio de plantas para a revegetação do local, devem ser consideradas as respostas em longo prazo. A sucessão de eventos com os anos, após a revegetação de uma área, em geral não é estudada. Um consórcio que se apresentou favorável na fase inicial pode não ser adequado no futuro, deixando a área com o solo descoberto e suscetível à ação dos fatores intempéricos. Dessa forma, este trabalho teve como objetivo monitorar as características associadas à contenção 
vegetativa e, em longo prazo, o surgimento de novas formas de cobertura ou exposição do solo, em resposta à revegetação com gramíneas e leguminosas em talude rodoviário de declividade acentuada.

\section{MATERIAL E MÉTODOS}

O ensaio foi implantado em dezembro de $1998 \mathrm{em}$ um talude de corte de um Latossolo VermelhoAmarelo, gerado por ocasião da pavimentação da BR 482, no subtrecho entre Viçosa e Araponga, MG, Brasil ( $20^{\circ} 44^{\prime}$ latitude S e $42^{\circ} 50^{\prime}$ longitude W) (Figura 1).

Os quatro blocos do experimento foram distribuídos em duas faces desse talude, com $75^{\circ}$ de inclinação. A localização das parcelas foi predominantemente em Horizonte $\mathrm{C}$, ficando algumas delas situadas em áreas
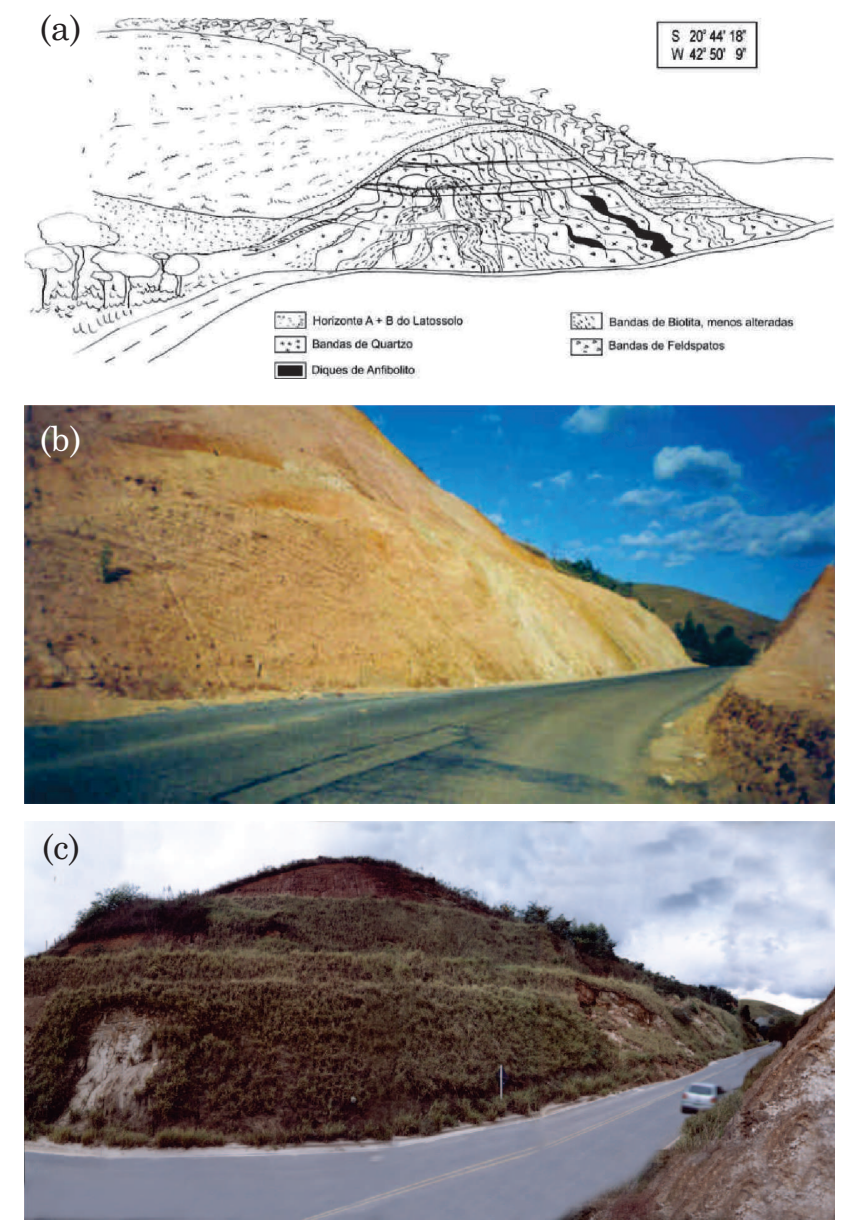

Figura 1. Corte esquemático ilustrando a variabilidade do solum $(A+B+C)$ na área onde foi instalado o experimento (saprolito de gnaisse) (a); vista geral do talude onde foi instalado o experimento (b); e quatro anos após a sua implantação $(c)$. de transição entre B e C. Os tratamentos, no esquema $1+3^{2}$, consistiram de uma testemunha e nove combinações de uma gramínea (Brachiaria brizantha, $B$. decumbens ou $B$. ruziziensis) e uma leguminosa [mucuna preta (Stizolobium aterrimum), feijãoguandu (Cajanus cajan) ou lab lab (Dolichos lab lab)]. A massa total de sementes por parcela sempre foi de $270 \mathrm{~g}$. As parcelas de $9 \mathrm{~m}^{2}(3 \times 3 \mathrm{~m})$, à exceção das testemunhas, foram coveadas e receberam a aplicação, a lanço, de uma mistura de $63 \mathrm{~g}$ de 8-28-16, $225 \mathrm{~g}$ de calcário dolomítico e $5 \mathrm{~L}$ de esterco bovino, acrescida da mistura de sementes correspondente a cada tratamento. Após a distribuição, as parcelas foram cobertas por tela ARP-430, uma biomanta resultante do entrelaçamento de fibras vegetais, que foi fixada na parcela por meio de grampos de aço.

Foram feitas duas avaliações, uma em agosto de 2002 e outra em abril de 2003 , identificando-se as seguintes "tipologias": cobertura de braquiária (BRA), leguminosa (LEG), capim-gordura (GOR), espécies invasoras (INV), biomanta (BIOM), resíduos em decomposição (RES), crostas microfíticas (CMICR), crosta física (CFIS), solo exposto (SOLEX), erosão (ERO) e afloramento de rochas (R).

Para quantificar as tipologias, em resposta aos tratamentos, realizaram-se dois levantamentos em 35 parcelas experimentais, nos períodos previamente indicados. Desde a implantação do ensaio, perderamse cinco parcelas por deslizamentos da encosta nesses locais.

Na quantificação das tipologias na superfície das parcelas, utilizou-se o método da corda (Olszevski et al., 1998), com algumas adequações. Uma corda de 3 $\mathrm{m}$ de comprimento foi marcada a cada $10 \mathrm{~cm}$ e fixada a dois pontos de apoio em um gabarito de metal. A identificação das tipologias foi feita deslocando-se a corda no sentido da declividade, a cada $10 \mathrm{~cm}$. Dessa forma, 961 pontos foram amostrados em cada parcela de $9 \mathrm{~m}^{2}$. Para fixar o gabarito ao solo, em cada parcela, foi fixada uma estaca de madeira em cada um dos quatro vértices dessa. Esse procedimento assegurou a mesma posição do gabarito nos dois levantamentos realizados. A partir desses resultados, quantificou-se o porcentual de cobertura de cada tipologia.

Com esses dados, confeccionaram-se mapas de cobertura para cada parcela experimental, com a utilização do software MS Excel para formatação e análises comparativas entre os dois levantamentos. Empregando-se a função condicional desse software, foram analisadas a distribuição espacial, a frequência, a dinâmica e a competição entre as tipologias encontradas nos dois levantamentos (Einloft, 2005). Fizeram-se as análises de cálculo da porcentagem de alteração na parcela experimental no período entre agosto de 2002 e abril de 2003 (1 $1^{\mathrm{a}}$ análise); a quantificação das tipologias na parcela em cada levantamento ( $2^{\mathrm{a}}$ análise); a comparação do segundo levantamento com o primeiro; e a verificação de qual o destino de cada quadrícula, quando analisada 
individualmente ( $3^{\mathrm{a}}$ análise): (i) ausente em ambos os levantamentos; (ii) presente somente no primeiro ou somente no segundo levantamento; e (iii) presente em ambos os levantamentos. $\mathrm{Na} 4^{\mathrm{a}}$ análise, determinou-se a frequência de cada situação da análise anterior e, na $5^{\mathbf{a}}$, analisou-se qual a tipologia mais competitiva no processo de dinâmica das parcelas. Após a análise anterior, na situação em que a tipologia só ocorria no primeiro levantamento, foi verificada qual a tipologia responsável pela sua substituição. $\mathrm{Na} 6^{\mathrm{a}}$ análise, determinou-se a frequência de cada substituição.

Os resultados obtidos para as porcentagens e dinâmicas das tipologias foram submetidos à análise de variância, desdobrando-se os graus de liberdade para tratamentos em contrastes ortogonais, que permitiram a comparação das braquiárias e leguminosas (Chew, 1976). Adotou-se a expressão "tendência" para indicar diferenças significativas entre 5 e $20 \%$, pelo teste $\mathrm{F}$.

\section{RESULTADOS E DISCUSSÃO}

\section{Identificação e quantificação das tipologias em agosto de 2002}

A região de Viçosa tem o clima marcado por duas estações: a chuvosa, de outubro a março, quando, em dezembro, a precipitação pluvial média chega a 245 $\mathrm{mm}$; e a seca, de abril a setembro, em que nos meses de junho a agosto a precipitação média total não ultrapassa $19 \mathrm{~mm}$. A precipitação pluviométrica da estação seca (abril a julho) que antecedeu o primeiro levantamento, em agosto de 2002, foi de apenas $43,2 \mathrm{~mm}$ (Eloi, 2001). Bochet et al. (2007) observaram que a disponibilidade de água no solo após as chuvas que ocorreram durante o período de germinação desempenhou papel importante na germinação de sementes e no processo de colonização de taludes rodoviários em ambientes semiáridos.

Nesse levantamento, foram identificadas 11 tipologias principais: braquiária (BRA), leguminosa (LEG), capim-gordura (GOR), espécies invasoras (INV), biomanta (BIOM), resíduos em decomposição (RES), crosta microfitica (CMICR), crosta física (CFIS), solo exposto (SOLEX), erosão (ERO) e afloramento de rochas $(R)$.

As tipologias podem ser agrupadas em cinco conjuntos. O primeiro é composto pelas espécies vegetais BRA e LEG, utilizadas nos tratamentos experimentais, acrescidas de GOR e INV, que são espécies invasoras presentes nas parcelas; o segundo contém material em decomposição, incluindo BIOM e RES; o terceiro é constituído de microrganismos e plantas inferiores (CMICR); o quarto é referente a formas de exposição do solo: CFIS, SOLEX e ERO; e o quinto é representado por afloramento de rochas (R).
A espécie invasora encontrada em maior proporção nas parcelas foi o capim-gordura, razão pela qual essa foi referida como tipologia (GOR), ficando em uma categoria diferente das demais plantas invasoras (INV). Identificaram-se, em acréscimo, nos dois levantamentos, 20 espécies invasoras, divididas entre nove famílias: Asteraceae, Poaceae, Verbenaceae, Malvaceae, Leguminoseae Papilionoideae, Pteridaceae, Melastomataceae, Blechnaceae e Lycopodiaceae. As famílias mais expressivas foram Asteraceae e Poaceae. Entre as espécies invasoras encontradas, predominaram as herbáceas, subarbustivas e arbustivas, comumente encontradas em áreas de regeneração natural nessa região. De maneira geral, essas plantas apresentam alta plasticidade fenotípica, à exceção das espécies da família Lycopodiaceae, que têm preferências por áreas mais úmidas e sombreadas.

No terceiro grupo, vale ressaltar que a crosta microfítica (CMICR) compreende a ocorrência de crosta biológica em uma fase inicial ou com presença de musgos e liquens.

Considerando o quarto grupo listado, a denominação CFIS diferencia-se de SOLEX por apresentar uma superfície com aparência selada, firme ao toque da vareta. A denominação $R$ (afloramento de rochas) apresentada no quinto grupo correspondeu à presença de quartzo e saprolito de gnaisse, em ordem decrescente de ocorrência, do tamanho de cascalhos e calhaus.

Um exemplo do mapeamento das tipologias nas parcelas é apresentado na figura 2, que ilustra o levantamento em uma parcela que recebeu o consórcio entre a $B$. decumbens e a mucuna-preta. Nessa parcela, observaram-se somente nove das 11 tipologias previamente listadas: braquiária (BRA), espécies invasoras (INV), biomanta (BIOM), resíduos em decomposição (RES), crosta microfítica (CMICR), crosta física (CFIS), solo exposto (SOLEX), erosão (ERO) e afloramento de rochas (R). Dessas, SOLEX, CMICR e BIOM apresentaram as maiores proporções (Figura 2).

Todas as parcelas tiveram suas tipologias mapeadas de forma semelhante. Com os dados levantados para cada tratamento, foram calculadas proporções de ocorrência (Quadro 1) e analisadas estatisticamente, comparando-se os tratamentos por meio de contrastes ortogonais (Quadro 2). Pelo fato de a ocorrência do afloramento de rocha ter sido excluída no cálculo das proporções, as tabelas apresentam apenas 10 das 11 tipologias previamente indicadas.

De maneira geral, com o levantamento realizado nas demais parcelas experimentais, verificou-se alta variabilidade de tipologias. Isso de certa forma era esperado, uma vez que diferentes coberturas proporcionadas pelos consórcios vegetais levariam a diferentes exposições do solo e, consequentemente, existiria a possibilidade do surgimento de novas tipologias. 
Quadro 1. Porcentagem de cobertura de braquiária (BRA), leguminosa (LEG), capim-gordura (GOR), espécies invasoras (INV), biomanta (BIOM), resíduos em decomposição (RES), crostas microfíticas (CMICR), crosta física (CFIS), solo exposto (SOLEX) e erosão (ERO) nos levantamentos realizados em agosto de 2002, abril de 2003 e dinâmica no período

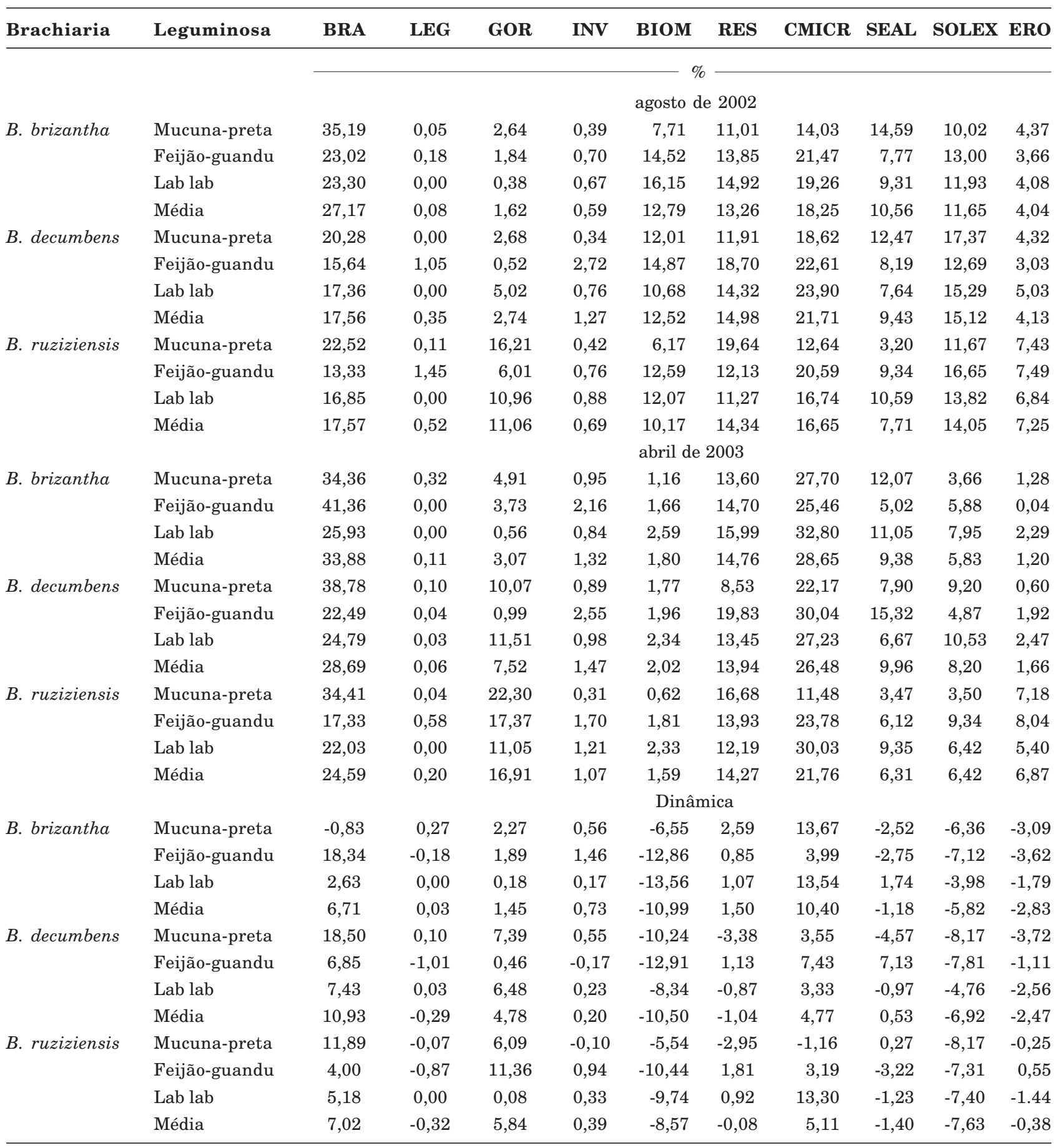

Foi observado que das três leguminosas utilizadas nos tratamentos apenas o feijão-guandu e a mucunapreta permaneceram no sistema até o quinto ano de implantação do experimento. Entretanto, os registros de mucuna-preta foram muito baixos, aparecendo em algumas situações como planta invasora e não na parcela originalmente semeada com essa leguminosa. $\mathrm{O}$ feijão-guandu apareceu em proporções maiores que as de mucuna, mas seus registros também foram extremamente baixos (Quadro 1).

Aparentemente, os espaços deixados pelas leguminosas foram ocupados pela gramínea do 
Quadro 2. Contrastes ortogonais comparando as porcentagens de coberturas das tipologias nos levantamentos realizado em agosto de 2002 , abril de 2003 e dinâmica no período

\begin{tabular}{|c|c|c|c|c|c|c|c|c|c|}
\hline Brachiaria & Leguminosa & $\mathbf{C}_{\mathbf{1}}$ & $\mathbf{C}_{2}$ & $\mathbf{C}_{3}$ & $\mathbf{C}_{4}$ & $\mathbf{C}_{5}$ & $\mathbf{C}_{6}$ & $\mathbf{C}_{7}$ & $\mathbf{C}_{8}$ \\
\hline \multirow[t]{3}{*}{ B. brizantha } & Mucuna-preta & 1 & 1 & 1 & 1 & 0 & 0 & 0 & 0 \\
\hline & Feijão-guandu & 1 & 1 & 1 & -1 & 0 & 0 & 0 & 0 \\
\hline & Lab lab & 1 & 1 & -2 & 0 & 0 & 0 & 0 & 0 \\
\hline \multirow[t]{3}{*}{ B. decumbens } & Mucuna-preta & 1 & -1 & 0 & 0 & 1 & 1 & 0 & 0 \\
\hline & Feijão-guandu & 1 & -1 & 0 & 0 & 1 & -1 & 0 & 0 \\
\hline & Lab lab & 1 & -1 & 0 & 0 & -2 & 0 & 0 & 0 \\
\hline \multirow[t]{4}{*}{ B. ruziziensis } & Mucuna-preta & -2 & 0 & 0 & 0 & 0 & 0 & 1 & 1 \\
\hline & Feijão-guandu & -2 & 0 & 0 & 0 & 0 & 0 & 1 & -1 \\
\hline & Lab lab & -2 & 0 & 0 & 0 & 0 & 0 & -2 & 0 \\
\hline & \multicolumn{9}{|c|}{ agosto de 2002} \\
\hline Braquiária & & 9,59 & 9,61 & 11,61 & $12,17^{\#}$ & 1,20 & 4,64 & 2,15 & 9,19 \\
\hline Leguminosa & & $-0,61$ & $-0,27$ & 0,23 & $-0,13$ & 1,05 & $-1,05^{*}$ & $1,56^{\#}$ & $-1,34^{*}$ \\
\hline Capim-gordura & & $-17,76$ & $-1,12$ & 3,72 & 0,80 & $-6,84$ & 2,16 & 0,30 & $10,20^{*}$ \\
\hline Espécies invasoras & & 0,48 & $-0,68$ & $-0,25$ & $-0,31$ & 1,54 & $-2,38^{*}$ & $-0,58$ & $-0,34$ \\
\hline Biomanta & & 4,97 & 0,27 & $-10,07^{\#}$ & $-6,81^{*}$ & 5,54 & $-2,88$ & $-5,38$ & $-6,42^{*}$ \\
\hline Resíduos em decomposição & & $-0,44$ & $-1,72$ & $-4,89$ & $-2,84$ & 1,97 & $-6,79$ & 9,23 & $7,51^{\#}$ \\
\hline Crostas microfíticas & & 6,66 & $-3,46$ & $-3,02$ & $-7,44^{\#}$ & $-6,57$ & $-3,99$ & $-0,25$ & $-7,95^{\#}$ \\
\hline Crosta física & & 4,57 & 1,13 & 3,74 & $6,82^{\#}$ & 5,38 & 4,28 & $-8,64$ & $-6,14^{\#}$ \\
\hline Solo exposto & & $-1,33$ & $-3,47$ & $-0,84$ & $-2,98$ & $-0,52$ & 4,68 & 0,68 & $-4,98$ \\
\hline \multirow[t]{2}{*}{ Erosão } & & $-6,33$ & $-0,09$ & $-0,13$ & 0,71 & $-2,71$ & 1,29 & 1,24 & $-0,06$ \\
\hline & \multicolumn{9}{|c|}{ abril de 2003} \\
\hline Braquiária & & 13,39 & 5,19 & $23,86^{\#}$ & $-7,00$ & 11,69 & $16,29^{\#}$ & 7,68 & $17,08^{\#}$ \\
\hline Leguminosa & & $-0,23$ & 0,05 & 0,32 & 0,32 & 0,08 & 0,06 & $0,62^{\#}$ & $-0,54^{\#}$ \\
\hline Capim-gordura & & $-23,23$ & $-4,45$ & 7,52 & 1,18 & $-11,96$ & $9,08^{\#}$ & 17,57 & 4,93 \\
\hline Espécies invasoras & & 0,71 & $-0,15$ & 1,43 & $-1,21^{\#}$ & 1,48 & $-1,66^{*}$ & $-0,41$ & $-1,39^{\#}$ \\
\hline Biomanta & & 0,64 & $-0,22$ & $-2,36$ & $-0,5$ & $-0,95$ & $-0,19$ & $-2,23$ & $-1,19$ \\
\hline Resíduos em decomposição & & 0,16 & 0,82 & $-3,68$ & $-1,1$ & 1,46 & $-11,30^{\#}$ & 6,23 & 2,75 \\
\hline Crostas microfíticas & & 11,61 & 2,17 & $-12,44$ & 2,24 & $-2,25$ & $-7,87$ & $-24,80^{*}$ & $-12,30^{\#}$ \\
\hline Crosta física & & 6,72 & $-0,58$ & $-5,01$ & 7,05 & 9,88 & $-7,42^{\#}$ & $-9,11$ & $-2,65$ \\
\hline Solo exposto & & 1,19 & $-2,37$ & $-6,36$ & $-2,22$ & $-6,99^{\#}$ & $4,33^{\#}$ & 0,00 & $-5,84^{\#}$ \\
\hline \multirow[t]{2}{*}{ Erosão } & & $-10,88$ & $-0,46$ & $-3,26$ & 1,24 & $-2,42$ & $-1,32$ & 4,42 & $-0,86$ \\
\hline & \multicolumn{9}{|c|}{ Dinâmica } \\
\hline Braquiária & & 3,60 & $-4,22$ & 12,26 & $-19,17^{*}$ & 10,49 & $11,65^{\#}$ & 5,53 & 7,89 \\
\hline Leguminosa & & 0,38 & 0,26 & 0,09 & $0,45^{\#}$ & $-0,97^{\#}$ & $1,11^{*}$ & $-0,94^{\#}$ & $0,80 *$ \\
\hline Capim-gordura & & $-5,45$ & $-3,33$ & 3,80 & 0,38 & $-5,11$ & $6,93^{\#}$ & $17,29 *$ & $-5,27$ \\
\hline Espécies invasoras & & 0,15 & 0,53 & 1,68 & $-0,90$ & $-0,08$ & 0,72 & 0,18 & $-1,04$ \\
\hline Biomanta & & $-4,35$ & $-0,49$ & 7,71 & $6,30^{\#}$ & $-6,47$ & 2,67 & 3,50 & $4,90^{\#}$ \\
\hline Resíduos em decomposição & & 0,63 & 2,54 & 1,30 & 1,74 & 0,51 & $-4,51$ & $-2,98$ & $-4,76^{\#}$ \\
\hline Crostas microfíticas & & 4,95 & 5,63 & $-9,42$ & $9,68^{\#}$ & 4,32 & $-3,88$ & $-24,60^{*}$ & $-4,35$ \\
\hline Crosta física & & 2,15 & $-1,71$ & $-8,75$ & 0,23 & 4,50 & $-11,7^{*}$ & $-0,49$ & 3,49 \\
\hline Solo exposto & & 2,52 & 1,10 & $-5,52$ & 0,76 & $-6,46$ & $-0,34$ & $-0,68$ & $-0,86$ \\
\hline Erosão & & $-4,52$ & $-0,36$ & $-3,13$ & 0,53 & 0,29 & $-2,60$ & 3,18 & $-0,80$ \\
\hline
\end{tabular}

*, \# significativo a 5 e $20 \%$, respectivamente, pelo teste $\mathrm{F}$.

consórcio vegetal ou por espécies invasoras, tendo como destaque o capim-gordura. A elevada proporção dessa gramínea se deve, provavelmente, à grande fonte de propágulos situada em cota acima das parcelas experimentais. Essas características são extremamente favoráveis à colonização vegetal (McClanahan, 1986; Martins et al., 2004).

Com relação às proporções das tipologias nas parcelas, as maiores de BRA foram encontradas nos tratamentos $\operatorname{com} B$. brizantha. Essa maior proporção 
justificaria a menor presença de capim-gordura e espécies invasoras nos tratamentos com essa gramínea, indicando maior competitividade da espécie (Quadro 1). Cóser et al. (1993) observaram, com o decorrer das avaliações, redução do componente capimgordura e consequente aumento da porcentagem de braquiária. De maneira contrária ao ocorrido $\operatorname{com} B$. brizantha, nos tratamentos com $B$. ruziziensis, principalmente quando associados à mucuna-preta, encontraram-se proporções significativas de GOR (Quadro 2), o que pode estar associado às diferenças de exigências entre as espécies de $B$. brizantha e $B$. ruziziensis. Botrel et al. (1999), ao avaliarem a produção de matéria seca e cobertura do solo de gramíneas forrrageiras na região sul de Minas Gerais, também observaram melhor desempenho da $B$. brizantha em relação à $B$. ruziziensis. Considerando a média geral para os tratamentos da $B$. ruziziensis, as proporções da tipologia GOR são semelhantes às da gramínea usada no consórcio. Em algumas parcelas, a imagem fornecida pelo mapa evidencia claramente a competição onde cada espécie procura a supressão e a ocupação da parcela.

As outras tipologias que se destacaram nesse levantamento foram INV, BIOM, CMICR e CFIS. As espécies invasoras, apesar de apresentarem-se em pequenas proporções, evidenciaram diferenças significativas, sendo superiores ao consórcio entre $B$. decumbens e feijão-guandu (Quadro 2). Já a biomanta apresenta-se mais ligada aos consórcios com feijãoguandu, sendo suas proporções significativamente maiores quando esse é consorciado com $B$. brizantha e $B$. ruziziensis (Quadros 1 e 2).

Com relação às crostas microfítica e física, foram verificadas algumas tendências. De forma similar à da biomanta, as crostas microfíticas parecem associadas aos consórcios entre feijão-guandu e $B$. brizantha e $B$. ruziziensis. Para a crosta física, as maiores proporções são relacionadas aos consórcios entre $B$. brizantha e mucuna-preta e entre $B$. ruziziensis e feijão-guandu (Quadros 1 e 2).

\section{Quantificação das tipologias em abril de 2003}

No segundo levantamento (abril de 2003) e respectivo mapeamento, foram observadas apreciáveis mudanças quanto às proporções das tipologias. De forma geral, houve favorecimento do crescimento vegetal na área, em razão do período chuvoso ocorrido no intervalo entre os dois levantamentos. A precipitação pluviométrica registrada no período foi de $1.163 \mathrm{~mm}$; a do mês mais chuvoso, janeiro, de 433 $\mathrm{mm}$. Na figura 2 , é apresentada a mesma parcela do tratamento do consórcio entre $B$. decumbens e mucuna-preta, com dados coletados em agosto de 2002. A exemplo da maioria das parcelas, o mapeamento após o período chuvoso ilustra o grande crescimento da braquiária, diminuindo a ocorrência de outras tipologias. Entre as braquiárias, a $B$. brizantha mantém as maiores médias de cobertura (Quadro 1).
O capim-gordura também apresentou crescimento expressivo em alguns tratamentos. De modo similar ao ocorrido no primeiro levantamento, seu crescimento é bem evidenciado nos tratamentos que incluíram a B. ruziziensis (Quadro 1). O capim-gordura é uma espécie muito agressiva, dominando rapidamente a área aonde chega; esse espalha-se pelas áreas adjacentes, excluindo algumas espécies já existentes, o que é corroborado por Martins et al. (2004). Apesar de a característica agressividade ser interessante para a recuperação de áreas degradadas, o comportamento do capim-gordura pode retardar ou impossibilitar a chegada de propágulos de espécies ecologicamente mais evoluídas. Outra característica desfavorável, principalmente para o setor de estradas de rodagens, é que por causa da grande quantidade de biomassa combustível produzida por essa espécie, especialmente no período seco, pode ocorrer alteração do regime de fogo das áreas invadidas, aumentando a frequência, área e intensidade do fogo (D’Antonio \& Vitousek, 1992; Brooks et al., 2004). Além disso, essa gramínea possui compostos e resinas oleaginosas e acumula grande biomassa morta, favorecendo assim as queimadas (Berardi, 1994).

Além do aumento das proporções de BRA e GOR no segundo levantamento, as crostas microfíticas apresentaram elevado crescimento, com efeito significativo nos consórcios entre $B$. ruziziensis e lab lab (Quadro 2). Os organismos constituintes da CMICR são pioneiros no processo de sucessão. Como são fotossintetizantes, precisam de luz para seu desenvolvimento. Esse consórcio provavelmente permitiria uma exposição ótima da superfície do solo à luz solar.

O levantamento de abril de 2003 evidenciou também que parcelas que apresentaram elevada incidência de crostas físicas em agosto de 2002 não tiveram essas superfícies cobertas por vegetação. Essa constatação mostraria a dificuldade apresentada na emergência de novas plantas, pela resistência própria da formação de selamento superficial. Essa inferência é reforçada, uma vez que foi observada a oferta de sementes das espécies vegetais utilizadas nos consórcios sobre a superfície do solo e, no período, não houve problemas relacionados à falta de água.

\section{Dinâmica das tipologias no período de agosto de 2002 a abril de 2003}

Com os dados dos dois últimos levantamentos, calculou-se a dinâmica das tipologias no período (Quadro 1). Para isso, dos valores de cada uma das tipologias no levantamento de abril de 2003, foram subtraídos aqueles determinados em agosto de 2002. Esse procedimento foi realizado com cada quadrícula de cada parcela experimental.

A dinâmica no período indicado, em resposta aos tratamentos originalmente impostos, é apresentada no quadro 1 . Nesse quadro, valores com sinal positivo indicam incremento médio da tipologia em abril de 
2003, com relação ao valor determinado em agosto de 2002. O sinal negativo evidencia diminuição da tipologia no mesmo intervalo. Os dados foram analisados estatisticamente e os contrastes correspondentes são apresentados no quadro 2.

No quadro 3, são apresentadas as substituições das tipologias nas quadrículas, em cada parcela entre os dois levantamentos. A parcela experimental apresentada na figura 2a,b evidencia uma das maiores variações observadas entre os dois levantamentos. Nessa parcela, $79 \%$ das quadrículas apresentaram tipologias diferentes no segundo levantamento, quando comparado ao primeiro. A análise dos dados indica grande variabilidade registrada nas parcelas experimentais, com a consequente dificuldade de evidenciar diferenças estatisticamente significativas (Quadro 2), mesmo que fossem registradas modificações de importância na dinâmica das tipologias (Quadro 1).

Após essas considerações, registraram-se respostas genéricas decorrentes das modificações que se seguiram ao período chuvoso, indicativas do dinamismo do sistema em estudo. Pelo quadro 1, observa-se que, como era de se esperar, a chuva registrada no período favoreceu o crescimento das plantas, com destaque para as braquiárias. A maior dinâmica no período foi para $B$. decumbens. Seu consórcio com mucuna-preta apresentou o maior incremento entre todos os tratamentos $(18,5 \%)$.

O único tratamento que não foi registrado incremento foi o do consórcio da $B$. brizantha com a mucuna-preta. Isso seria justificado porque, nesse tratamento, a braquiária apresentou crescimento destacadamente superior no levantamento de agosto de 2002, em relação ao dos outros em análise. Observou-se proporção de $35,19 \%$, comparada à média de $19,04 \%$ nos outros tratamentos, com baixo desvio (Quadro 1).

Seguindo as braquiárias, em ordem decrescente, escalaram-se o capim-gordura e as outras espécies invasoras. Esse último conjunto, porém, apresentou variação porcentual reduzida. As leguminosas, de forma geral, continuaram em declínio, diminuindo ainda mais a já escassa presença no levantamento de agosto de 2002 (Quadro 1).

O período chuvoso favoreceu também o crescimento das crostas microfíticas. Nos consórcios com $B$. brizantha, o incremento médio foi de $57 \%$ (Quadro 1). A importância do crescimento das espécies vegetais nesse período é destacada porque a parte aérea das plantas intercepta as gotas das chuvas, diminuindo a sua energia e evitando, assim, a desagregação das partículas e o selamento superficial. Outra função desempenhada pela cobertura vegetal é atenuar a variação de temperatura na superfície do solo, reduzindo a amplitude nos ciclos de umedecimento e secagem da superfície do solo (Fullen, 1998; Robinson \& Phillips, 2001).

O levantamento realizado em abril de 2003 apresentou a diminuição das três formas de exposição do solo, todas essas críticas na revegetação de taludes: solo exposto, solo erodido e presença de crosta física; nessa ordem, apresentaram valores sensivelmente inferiores (Quadro 1).

Essa diminuição pode ter sido verificada em resposta ao incremento da cobertura vegetal ou da presença das crostas microfíticas. Outra possibilidade, considerando que a menor alteração foi registrada para as crostas físicas, seria a formação dessas a partir das outras duas formas de exposição do solo.

A diminuição da erosão poderia ser atribuída também à transformação de material orgânico, contribuindo para iniciar o processo de agregação próximo à superfície do solo. Observa-se que a biomanta apresentou, em todos os consórcios, dinâmica com sinal negativo, o que indica sua retirada do sistema. O caminho mais lógico é a sua transformação em resíduos em decomposição. A pouca variação dessa tipologia indica razoável equilíbrio entre acréscimo e

Quadro 3. Substituição de tipologias nas quadrículas das parcelas experimentais, no período entre agosto de 2002 e abril de 2003

\begin{tabular}{|c|c|c|c|c|c|}
\hline \multicolumn{2}{|c|}{ Tratamento } & \multicolumn{4}{|c|}{ Alteração na parcela } \\
\hline Braquiária & Leguminosa & Bloco I & Bloco II & Bloco III & Bloco IV \\
\hline \multirow[t]{3}{*}{ B. brizantha } & Mucuna-preta & 71,6 & 40,7 & 57,1 & - \\
\hline & Feijão-guandu & - & 63,8 & 67,2 & 68,9 \\
\hline & Lab lab & 71,0 & 37,5 & 71,2 & 65,7 \\
\hline \multirow[t]{3}{*}{ B. decumbens } & Mucuna-preta & 73,0 & 70,5 & 70,1 & 79,0 \\
\hline & Feijão-guandu & 71,6 & 45,7 & 72,2 & 68,0 \\
\hline & Lab lab & 78,2 & 58,6 & 65,5 & 71,1 \\
\hline \multirow[t]{3}{*}{ B. ruziziensis } & Mucuna-preta & 60,8 & 59,0 & - & 64,2 \\
\hline & Feijão-guandu & 69,7 & 78,3 & 75,9 & 68,3 \\
\hline & Lab lab & 69,3 & 72,5 & 74,2 & 66,0 \\
\hline
\end{tabular}


degradação no período. Assim, a degradação parcial da biomanta deveria ser, necessariamente, acompanhada pela transformação dos resíduos em decomposição em materiais menores, não identificáveis sob essa denominação na observação visual realizada nas parcelas experimentais (Quadro 1).

\section{Observações qualitativas da competição entre tipologias}

Além de quantificar a dinâmica no período, também foi possível analisar a capacidade de competição de cada tipologia em relação às demais. Comparando o segundo levantamento com o primeiro, cada tipologia poderia estar presente em ambos os levantamentos, somente no primeiro ou somente no segundo levantamento, quando analisada cada quadrícula individualmente. Depois dessa análise, na situação em que só ocorria no primeiro levantamento, foi verificada qual a tipologia responsável pela sua substituição. Esse procedimento foi adotado em todas as parcelas e em cada uma das 11 tipologias analisadas, determinando-se as características de competição.

O trabalho é exemplificado na figura 3 , que apresenta a mesma parcela do consórcio entre $B$. decumbens e mucuna-preta, previamente evidenciada (Figura 2). Considerando a necessidade de elaborar 11 figuras por parcela experimental, na figura 3 indica-se somente a competição da braquiária, que foi a tipologia mais destacada nos levantamentos. Nessa figura, é ilustrada a competição dessa tipologia em relação às demais na parcela. Foi verificado que no levantamento de abril de 2003 a B. decumbens passou a ocupar 582 novas células, o que representa aumento de $59 \%$ de novas ocorrências. De forma oposta, em 14 situações, a BRA foi substituída por outra tipologia. Segundo o mapa, seis quadrículas (células) foram substituídas por CMICR, três por SOLEX, duas por BIOM, duas por RES e uma por INV.

A análise de dinâmica e competição entre tipologias foi uma tentativa de conhecer uma sequência de eventos em uma área recém-aberta por algum evento de degradação. A complexidade da apresentação dos dados leva à realização de observações qualitativas, mesmo que a totalidade das 35 parcelas tenha sido levantada para estabelecer a competição entre as 11 tipologias. As observações mencionadas surgem do estudo de 385 mapas semelhantes aos da figura 2 .

A análise das parcelas-testemunhas, exatamente por não haver presença inicial de plantas, simula bem a dinâmica, após abertura e exposição de uma área degradada. No levantamento de agosto de 2002 , quatro anos após a construção do talude, foram observadas nas parcelas testemunhas as seguintes tipologias, em ordem decrescente de ocorrência: CMICR, CFIS, GOR, SOLEX e ERO.

Os dados de abril de 2003 permitiram observar que as áreas (células) de SOLEX, no levantamento de agosto de 2002, foram colonizadas por crostas microfíticas e espécies invasoras (GOR e INV) ou, ainda, deram lugar à CFIS. Com relação ao capimgordura, essa gramínea colonizou áreas com solo exposto (SOLEX e CFIS) ou CMICR, sendo a maior proporção observada nesta última.

Nas demais parcelas, revegetadas com espécies vegetais (consórcios), as dinâmicas das células

(a)

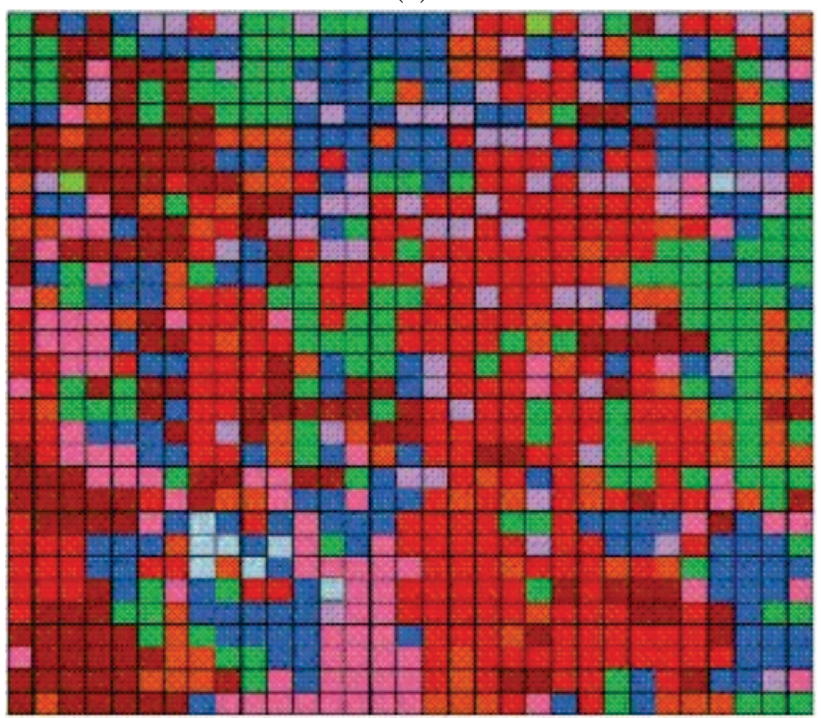

(b)

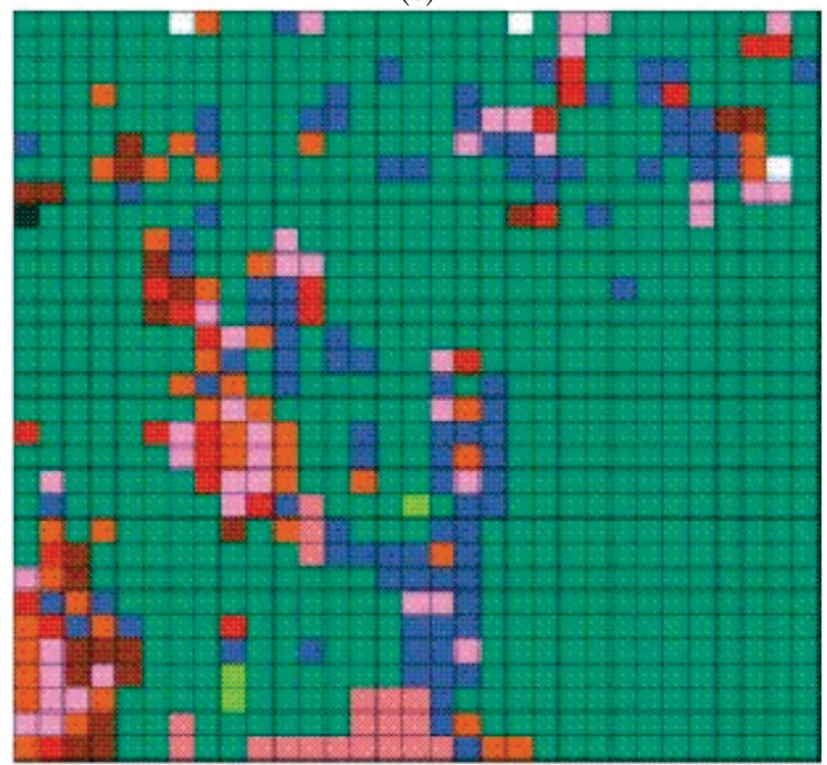

Braquiária

Resíduos em decomposição

- Espécies invasoras

Solo exposto

Crosta microfítica

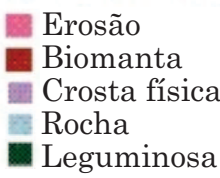

Figura 2. Mapeamento das tipologias encontradas em parcela experimental nos levantamentos de agosto de 2002 (a) e abril de 2003 (b). $O$ exemplo corresponde ao consórcio entre Brachiaria decumbens e mucuna-preta. 


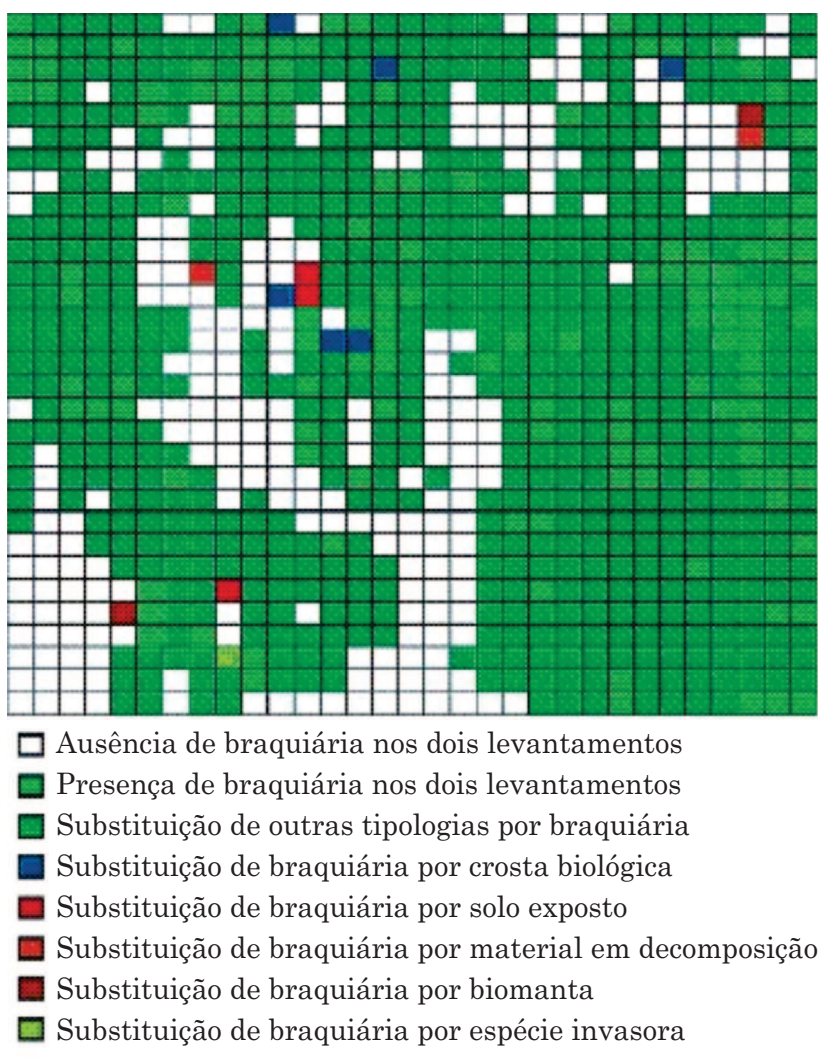

Figura 3. Competição entre a braquiária e as demais tipologias encontradas em parcela experimental no levantamento de abril de 2003. O exemplo corresponde ao consórcio entre Brachiaria decumbens e mucuna-preta.

SOLEX, CFIS e CMICR levaram, respectivamente, à colonização de BRA, CMICR e BRA. De modo similar ao ocorrido nas parcelas testemunhas, onde a colonização de plantas invasoras era preferencialmente em células de CMICR, o aparecimento de novas plantas de braquiária em parcelas revegetadas apresentou o mesmo comportamento. $\mathrm{O}$ número de ocorrência de novas plantas em locais com CMICR foi o dobro da ocorrência em SOLEX. Isso pode ser o reflexo da importância das crostas microfíticas no estádio primário da sucessão ecológica, resultando na estabilização e recuperação de superfícies degradadas ao disponibilizarem elementos essenciais à instalação de plantas invasoras (Leonard et al., 1995).

A análise de competição entre as tipologias sugeriu propensão à sucessão de respostas, após a degradação de uma área. Entretanto, observa-se também a existência de eventos paralelos que contrariam essa sequência, o que foi bem ilustrado em situações em que, no levantamento de agosto de 2002, em algumas células, notou-se CMICR e, no de abril de 2003, detectou-se a presença de CFIS. A explicação para o fato seria a provável ocorrência de erosão no período compreendido entre os dois levantamentos, que soterrou a crosta microfítica, atrasando o processo de colonização por espécies vegetais.

\section{CONCLUSÕES}

1. As espécies vegetais (braquiária, leguminosa e invasoras) e as crostas microfíticas foram as mais importantes na contenção do talude estudado, das 11 tipologias encontradas. As crostas microfíticas foram de grande importância no estádio primário da sucessão ecológica, resultando na estabilização e recuperação das superfícies degradadas, o que favorece a instalação de plantas invasoras.

2. A variação sazonal entre as estações seca e chuvosa acarretou diminuição da erosão e do solo exposto, pelo incremento da cobertura vegetal e das crostas microfíticas.

\section{LITERATURA CITADA}

BERARDI, A. Effects of the african grass Melinis minutiflora on the plant community composition and the fire characteristics of a central Brazilian savanna. London: University College, 1994. 49p. (Dissertação de Mestrado)

BOCHET, E.\& GARCIA-FAYOS, P. Factors controlling vegetation stablishment and water erosion on motorway slopes in Valencia, Spain. Rest. Ecol., 12:166-174, 2004.

BOCHET, E.; GARCIA-FAYOS, P.; ALBORCH B. \& TORMO J. Soil water availability effects on seed germination account for species segregation in semiarid roadslopes. Plant Soil, 295:179-191, 2007.

BOTREL, M.A.; ALVIM, M.J. \& XAVIER, D.F. Avaliação de gramíneas forrageiras na região sul de Minas Gerais. Pesq. Agropec. Bras., 34:683-689, 1999.

BROOKS, M.L.; D'ANTONIO, C.M.; RICHARDSON, D.M.; GRACE, J.B.; KEELEY, J.E.; DITOMASO, J.M.; HOBBS, R.J.; PELLANT, M. \& PYKE, D. Effects of invasive alien plants on fire regimes. BioScience, 54:677-688, 2004.

CHEW, V. Comparing treatment means: a compendium. HortScience, 11:348-356, 1976.

CÓSER, A.C.; CRUZ FILHO, A.B.; MARTINS, C.E. \& FREITAS, V.P. Modificação da composição botânica em pastagens de capim-gordura e braquiária, sob pastejo. Past. Trop., 15:9-12, 1993.

D'ANTONIO, C.M. \& VITOUSEK, P.M. Biological invasions by exotic grasses, the grass/fire cycle, and global change. Ann. Rev. Ecol. Syst., 23:63-87, 1992.

EINLOFT, R. Monitoramento de características associadas à contenção vegetativa em talude rodoviário de saprolito de gnaisse, Zona da Mata de Minas Gerais. Viçosa: Universidade Federal de Viçosa, 2005. 95p. (Tese de Doutorado) 
EINLOFT, R.; OZORIO, T.F. \& SILVA JUNIOR, W.M. Técnicas de revegetação para recuperação de áreas degradadas. Ação Amb., 10:19-20, 2000.

EINLOFT, R.; RUIZ, H.A.; GRIFFITH, J.J.; SCHAEFER, C.E.G.R. \& COSTA, L.M. Índice de priorização para avaliar a contenção vegetativa em talude rodoviário de saprolito de gnaisse, na Zona da Mata de Minas Gerais. Bragantia, 68:205-214, 2009.

ELOI, C.M.A. Enquadramento das "Zonas de Vida" de Holdridge na classificação climática de Minas Gerais. Viçosa: Universidade Federal de Viçosa, 2001. 126p. (Dissertação de Mestrado)

FOSTER, B.L.; MURPHY, C.A.; KELLER, K.R.; ASCHENBACH, T.A.; QUESTAD, E.J. \& KINDSCHER, K. Restoration of prairie community structure and ecosystem function in an abandoned hayfield: a sowing experiment. Rest. Ecol., 15:652$661,2007$.

FULLEN, M.A. Effects of grass ley set-aside on runoff, erosion and organic matter levels in sandy soils in East Shropshire, UK. Soil Tillage Res., 46:42-49, 1998.

GRIFFITH, J.J.; DIAS, L.E. \& JUCKSCH, I. Novas estratégias ecológicas para a revegetação de áreas mineradas no Brasil. In: RECUPERAÇÃO DE ÁREAS DEGRADADAS. SIMPÓSIO SUL - AMERICANO, 1.: SIMPÓSIO NACIONAL, 2., Curitiba, 1994. Anais. Curitiba: Fundação de Pesquisas Florestais, 1994. p.31-43.
LEONARD, S.G.; ROSENTRETER, R. \& KARL, M.G. Microbiotic crusts: ecological roles and implications for rangeland management in the interior Columbia Basin and portions of the Klamath and Great Basin. 1995. 26p. Disponível em: <htpp://www.icbemp.gov/science/ leonard2.pdf>. Acesso em 12 de fev. de 2003.

MARTINS, C.R.; LEITE, L.L. \& HARIDASAN, M. Capimgordura (Melinis minutiflora P. Beauv.), uma gramínea exótica que compromete a recuperação de áreas degradadas em unidades de conservação. R. Árvore, 28:739-747, 2004.

McCLANAHAN, T.R. The effect of a seed source on primary succession in a forest ecosystem. Vegetatio, 65:175-178, 1986.

OLSZEVSKI, N.; BRAGA, A.P.; COSTA, L.M. \& SILVA, H.R.F. Proposição de metodologia para avaliação de pastagens em propriedades rurais. In: REUNIÃO BRASILEIRA DE MANEJO E CONSERVAÇÃO DO SOLO E DA ÁGUA, 12., Fortaleza, 1998. Anais. Fortaleza: Sociedade Brasileira de Ciência do Solo, 1998. p.304-305.

PASCHKE, M.W.; DELEO, C. \& REDENTE, E.F. Revegetation of roadcut slopes in Mesa Verde National Park, USA. Rest. Ecol., 8:276-282, 2000.

ROBINSON, D.A. \& PHILLIPS, C.P. Crust development in relation to vegetation and agricultural practice on erosion susceptible, dispersive clay soils from central and southern Italy. Soil Tillage Res., 60:1-9, 2001. 